\title{
Fracionamento de carboidratos e proteínas, cinética de degradação ruminal in vitro pela técnica de produção de gás, de rações suplementares contendo torta de girassol
}

[Fractionation of carbohydrates, protein and "in vitro" ruminal degradation kinetics by gas production technique of supplementary rations containing sunflower cake]

\author{
A.X. Santo ${ }^{1}$, L.D.F. Silva ${ }^{1}$, J.A.C. Lançanova ${ }^{2}$, E.L.A. Ribeiro ${ }^{1}$, I.Y. Mizubuti ${ }^{1}$, A.P.S. Fortaleza ${ }^{1}$, \\ É.L. Henz ${ }^{3}$, F.L.M. Júnior ${ }^{1}$ \\ ${ }^{1}$ Universidade Estadual de londrina - Londrina, PR \\ ${ }^{2}$ Instituto Agronômico do Paraná - Ibiporã, PR \\ ${ }^{3}$ Aluno de pós-graduação - Universidade Estadual de Londrina - Londrina, PR
}

\begin{abstract}
RESUMO
Objetivou-se neste estudo fracionar os carboidratos e as proteínas e avaliar a cinética de degradação ruminal de rações contendo $0 ; 24 ; 48$ e $72 \%$ de torta de girassol. Os carboidratos foram fracionados em $\mathrm{A}+\mathrm{B} 1, \mathrm{~B} 2$ e C, e as proteínas em A, B1+B2, B3 e C. Os parâmetros de cinética de degradação ruminal das rações foram estimados a partir do método semiautomático de produção cumulativa de gases in vitro. Foram utilizados quatro animais $1 / 2$ Gir x $1 / 2$ Holandês, machos e castrados, fistulados no rúmen, mantidos em pastagem e recebendo $1 \mathrm{~kg}$ de ração concentrada, como doadores de inócuo ruminal. $\mathrm{O}$ ensaio foi realizado em delineamento em blocos ao acaso, com quatro rações e quatro períodos, e os resultados obtidos foram interpretados de acordo com a análise de variância e de regressão a $5 \%$ de significância. Houve efeito linear decrescente para o fracionamento de carboidratos totais e a fração $\mathrm{A}+\mathrm{B} 1$, e efeito linear crescente sobre as frações B2 e C. Para as frações nitrogenadas, houve efeito linear crescente sobre a fração $\mathrm{A}$, e efeito linear decrescente sobre as frações B1+B2 e C. Em relação à cinética de degradação ruminal in vitro, houve efeito decrescente sobre o parâmetro "a", e efeito quadrático sobre os parâmetros "b" e "c", com pontos de máxima, respectivamente, de 61,84 e $66,77 \%$ de torta de girassol. A inclusão da torta de girassol nas rações suplementares, nos teores estudados, influenciou nas frações dos carboidratos, das proteínas e nos parâmetros de degradação ruminal. Caso haja a disponibilidade desse ingrediente, ele pode ser adicionado à ração suplementar de bovinos sem prejuízo nos parâmetros nutricionais e metabólicos.
\end{abstract}

Palavras-chave: avaliação de alimentos, coprodutos, taxa de degradação, ruminante

\begin{abstract}
This work aimed to fractionate carbohydrates and protein and to evaluate ruminal degradation kinetics of rations containing $0 ; 24 ; 48$ and $72 \%$ of inclusion of sunflower cake. The carbohydrates were fractionate in $A+B 1, B 2$ and $C$ fraction, and protein in $A, B 1+B 2, B 3$ and $C$. Rations ruminal degradation kinetics were realized with the "in vitro" semiautomatic gas production technique. Four male, castrated, 1/2 Gir x 1/2 Holstein were used, all of them fistulated in the rumen. This study was done in randomized block design with four rations and four periods. The results obtained were interpreted according to variance and regression analysis at 5\% significance level. There is a decreasing effect for total carbohydrates fractionation and $A+B 1$ fraction, and there is an increasing effect for B2 and $C$ fraction. For nitrogen fractions there is an increasing effect on fraction A and negative linear effect on $B 1+B 2$ and $C$ fractions. For "In vitro" ruminal degradation kinetics there is a decreasing effect for " $a$ " parameter, and quadratic effect for " $b$ " and " $c$ " parameters with maximum points respectively 61.84 and
\end{abstract}

Recebido em 22 de setembro de 2015

Aceito em 6 de julho de 2016

*Autor para correspondência (corresponding author)

E-mail: leandro@uel.br 
$66.77 \%$ of sunflower seed meal. The inclusion of sunflower cake in supplementary feeding, the studied levels, influenced the fractions of carbohydrates, proteins and degradation parameters. If there is the availability of this ingredient, it can be added to the supplemental feed cattle subject to the nutritional and metabolic parameters.

Keywords: coproducts, degradation rate, food evaluation, ruminant

\section{INTRODUÇ̃̃O}

O girassol (Helianthus annuus L.) é uma oleaginosa utilizada para extração do óleo destinado ao consumo há muitos anos, e, com o advento do biodiesel, vem sendo utilizado como cultura para exploração na produção de energia renovável. A torta e o farelo resultantes do esmagamento para extração do óleo têm potencial de serem utilizados na alimentação animal. Segundo Silva et al. (2007), a cultura apresenta ciclo curto e alta quantidade e qualidade de óleo, porém ainda é pouco difundida no Brasil.

Estudos foram realizados por Oliveira (2010), Mesacasa et al. (2012) e Santos et al. (2012) a fim de avaliar o desempenho e o comportamento de bovinos suplementados com torta de girassol em relação à fonte proteica tradicional e concluíram que a substituição parcial apresenta bons resultados. Santos et al. (2012) avaliaram o desempenho de vacas em lactação recebendo rações contendo $0 ; 24 ; 48$ e $72 \%$ de torta de girassol e relataram maior produção de leite em vacas alimentadas com rações contendo $24 \%$ de torta de girassol $(16,48 \mathrm{~kg}$ de leite/dia) e menor produção $(14,56 \mathrm{~kg}$ de leite/dia) ao incluírem $72 \%$ de torta de girassol; por outro lado, essa inclusão promoveu acréscimos no teor de gordura do leite $(3,96 \%)$. No entanto, são escassos os trabalhos que avaliaram o valor nutritivo desse ingrediente em rações suplementares.

Mello et al. (2006) afirmaram que o valor nutritivo de um alimento depende de sua composição química e do aproveitamento de seus nutrientes pelos animais, uma vez que nos animais ruminantes esse aproveitamento é resultante da simbiose entre o animal e a microbiota ruminal. É por meio da simbiose que ocorre a utilização indireta de carboidratos estruturais inacessíveis à ação enzimática dos mamíferos. Entretanto, a quantidade de nutrientes ingeridos e realmente absorvidos depende da taxa de fermentação ruminal e do tempo de permanência e exposição ao ataque microbiano, pois a fração efetivamente degradada é função das taxas de degradação e de passagem. Ainda, segundo os mesmos autores, a taxa e a extensão de degradação ruminal dependem principalmente da natureza e do teor dos componentes da parede celular e da disponibilidade ruminal de nitrogênio. Nesse sentido, o fracionamento de carboidratos $\mathrm{e}$ proteínas, juntamente com a cinética de degradação ruminal, possibilita a estimativa mais precisa do valor nutritivo dos alimentos.

Entre as técnicas empregadas nos sistemas que visam aperfeiçoar as informações nutritivas dos alimentos a fim de adequar dietas para os animais ruminantes, em relação à composição e características dos alimentos, pode-se destacar a técnica de produção cumulativa de gás. Essa técnica foi desenvolvida para estimar a taxa de fermentação de alimentos em ruminantes, por meio de incubação in vitro do alimento em líquido ruminal tamponado, medindo periodicamente o gás produzido, sendo este $\mathrm{o}$ indicativo da cinética de fermentação ruminal. Ao se utilizar o líquido ruminal para incubar um alimento, a fração degradada pode ser fermentada com produção de gases e ácidos, ou ser incorporada como biomassa microbiana. Assim sendo, as avaliações de degradação por meio das técnicas de produção de gás fornecem importantes informações em relação à fração do alimento que é fermentado no rúmen e à possível fração direcionada ao crescimento microbiano (Pereira et al., 2013).

Objetivou-se com este estudo avaliar os carboidratos e as proteínas por meio de seus fracionamentos e a cinética de degradação ruminal de rações suplementares com diferentes teores de torta de girassol.

\section{MATERIAL E MÉTODOS}

O ensaio foi realizado no Laboratório de Análises de Alimentos e Nutrição Animal (Lana) do Departamento de Zootecnia da Universidade 
Estadual de Londrina, entre os meses de fevereiro de 2013 e abril de 2014, com aprovação do Comitê de Ética em Experimentação Animal (Ceea), sob o n ${ }^{\circ} 62 / 08$, processo $n^{\circ} 18300 / 2008$. Foram estudadas rações similares às utilizadas por Santos et al. (2012), com os teores de $0 ; 24 ; 48$ e $72 \%$ de inclusão de torta de girassol, a fim de melhor avaliar o valor nutritivo dessas rações.

Foram realizadas as determinações da matéria seca (MS), da matéria mineral (MM), da proteína bruta (PB), do extrato etéreo (EE), da fibra em detergente neutro (FDN), da fibra em detergente ácido (FDA), da lignina em detergente ácido, obtida por meio de digestão ácida ( $\mathrm{H} 2 \mathrm{SO} 4$ a $72 \%$ ) (LDA), da proteína insolúvel em detergente neutro (PIDN) e da proteína insolúvel em detergente ácido (PIDA). A fibra em detergente neutro corrigida para os teores de cinza e proteína (FDNCP) foi determinada segundo métodos descritos por Silva e Queiroz (2002). O nutriente digestível total (NDT) dos ingredientes e das rações foi calculado pela fórmula NDT $=81,41-(0,6 *(\mathrm{FDA} * 0,08))$, citada por Chandler (1990), (Tab. 1 e 2).

Os carboidratos totais (CHO) foram determinados pela expressão $\mathrm{CHO}(\% \mathrm{MS})=100$ - \%PB - \%EE - \%MM (Sniffen et al., 1992). A fração $\mathrm{C}(\% \mathrm{CHO})$ foi obtida pela equação $\mathrm{LIG}$ $(\% \mathrm{FDN}) * 2,4$, descrita por Sniffen et al. (1992). Ainda segundo o mesmo autor, por meio da fórmula FDNCP - C (\%CHO), foi obtida a fração B2 $(\% \mathrm{CHO})$. A fração de carboidratos não estruturais, fração $\mathrm{A}+\mathrm{B} 1 \quad(\% \mathrm{CHO})$, foi determinada pela equação $100-(\% \mathrm{~PB}+\% \mathrm{EE}+$ $\%$ FDNCP $+\% \mathrm{MM})$, descrita por Sniffen et al. (1992).

Tabela 1. Composição bromatológica dos alimentos utilizados nas rações, expressa em (\%MS)

\begin{tabular}{ccccccc}
\hline \multirow{2}{*}{ Item } & \multicolumn{7}{c}{ Ingredientes $^{1}$} & $\begin{array}{c}\text { Farelo de } \\
\text { algodão }^{2}\end{array}$ & $\begin{array}{c}\text { Farelo de } \\
\text { soja }^{2}\end{array}$ & Milho $^{2}$ & $\begin{array}{c}\text { Torta de } \\
\text { girassol }^{2}\end{array}$ & $\begin{array}{c}\text { Silagem de } \\
\text { sorgo }^{3}\end{array}$ & $\begin{array}{c}\text { Suplemento } \\
\text { mineral }\end{array}$ \\
\cline { 2 - 7 } MS (\%MN) & 87,41 & 88,61 & 87,84 & 91,92 & 36,1 & 98,00 \\
MO (\%MS) & 94,86 & 93,76 & 98,28 & 93,86 & 92,22 & - \\
MM (\%MS) & 5,14 & 6,24 & 1,72 & 6,14 & 7,78 & - \\
PB (\%MS) & 26,99 & 50,38 & 10,05 & 32,43 & 7,61 & - \\
EE (\%MS) & 9,9 & 1,77 & 4,32 & 13,33 & 4,13 & - \\
FDN (\%MS) & 36,52 & 19,84 & 23,07 & 40,34 & 58,52 & - \\
FDA (\%MS) & 22,42 & 14,64 & 7,37 & 27,63 & 28,78 & - \\
FDN & 35,91 & 19,14 & 22,84 & 39,36 & 57,20 & - \\
(\%MS) & 0,0009 & 0,0051 & 0,0011 & 0,0023 & 0,0008 & - \\
PIDN (\%MS) & 0,0007 & 0,0028 & 0,0042 & 0,0016 & 0,0013 & - \\
PIDA (\%MS) & 6,44 & 1,27 & 1,10 & 4,59 & 3,11 & - \\
LDA (\%MS) & 57,97 & 41,61 & 83,91 & 48,10 & 71,79 & - \\
CHO (\%MS) & 22,06 & 22,47 & 61,07 & 8,74 & 23,28 & - \\
CNF (\%MS) & 0,61 & 0,69 & 0,23 & 0,98 & 1,42 & - \\
CIDN (\%MS) & 64,14 & 74,38 & 77,87 & 68,15 & 65,34 & - \\
NDT (\%MS) & &
\end{tabular}

${ }^{1}$ Abreviaturas: MS $(\% \mathrm{MS})=$ porcentagem de matéria seca na matéria natural; $\mathrm{MO}(\% \mathrm{MS})=$ porcentagem de matéria orgânica na matéria seca; MM $(\% \mathrm{MS})=$ porcentagem de matéria mineral na matéria seca; $\mathrm{PB}(\% \mathrm{MS})=$ porcentagem de proteína bruta na matéria seca; EE $(\% \mathrm{MS})=$ porcentagem de extrato etéreo na matéria seca; FDN $(\% \mathrm{MS})=$ porcentagem de fibra bruta em detergente neutro na matéria seca; FDA $(\% \mathrm{MS})=$ porcentagem de fibra em detergente ácido na matéria seca; $\mathrm{FDN}_{\mathrm{CP}}(\% \mathrm{MS})=$ porcentagem de fibra em detergente neutro corrigido para cinzas e proteínas na matéria seca; PIDN (\%MS)= porcentagem de proteína indigestível em nitrogênio neutro na matéria seca; PIDA $(\% \mathrm{MS})=$ porcentagem de proteína indigestível em detergente ácido na matéria seca; LDA $(\% \mathrm{MS})=$ porcentagem de lignina em solução de ácido sulfúrico $72 \%$ na matéria seca; $\mathrm{CHO}(\% \mathrm{MS})=$ porcentagem de carboidratos totais na matéria seca; $\mathrm{CNF}(\% \mathrm{MS})=$ porcentagem de carboidratos não fibrosos na matéria seca; $\mathrm{CIDN}(\% \mathrm{MS})=$ porcentagem de cinzas indigestível em detergente neutro; NDT $(\% \mathrm{MS})=$ porcentagem de nutrientes digestíveis totais na matéria seca. ${ }^{2} \mathrm{NDT}(\% \mathrm{MS})=81,41-\left(0,6^{*}\left(\mathrm{FDA}^{*} 0,08\right)\right)($ Chandler, 1990$) ;{ }^{3} \mathrm{NDT}(\% \mathrm{MS})=105,2-(0,68 * \% \mathrm{FDN})$ (Chandler, 1990). ${ }^{4} \mathrm{FDN}$ CP $(\% \mathrm{MS})=\mathrm{FDN}-\mathrm{PIDN}-\mathrm{CIDN}($ Sniffen et al., 1992$) ;{ }^{5} \mathrm{CHO}(\% \mathrm{MS})=100-(\% \mathrm{~PB}+\% \mathrm{EE}+\% \mathrm{MM})$ (Sniffen et al., 1992); ${ }^{6} \mathrm{CNF}(\% \mathrm{MS})=100-\left(\% \mathrm{~PB}+\% \mathrm{FDN}_{\mathrm{CP}}+\% \mathrm{EE}+\% \mathrm{MM}\right)($ Sniffen et al., 1992).

Fonte: Elaboração dos autores. 
Fracionamento de carboidratos...

Tabela 2. Proporção e composição químico-físicas das rações suplementares e completas, expressas em $(\% \mathrm{MS})$

\begin{tabular}{|c|c|c|c|c|}
\hline & \multicolumn{4}{|c|}{ Rações suplementares (teores de substituição da $\mathrm{TG}^{1}$ ) } \\
\hline Ingrediente (\% MS) & 0 & 24 & 48 & 72 \\
\hline Torta de girassol & 0,00 & 2,40 & 4,80 & 7,20 \\
\hline Farelo de algodão com casca & 10,00 & 7,60 & 5,20 & 2,80 \\
\hline Farelo de soja & 3,56 & 4,22 & 4,89 & 5,56 \\
\hline Milho & 84,44 & 83,79 & 83,11 & 82,44 \\
\hline Suplemento mineral & 2,00 & 2,00 & 2,00 & 2,00 \\
\hline Total & 100,00 & 100,00 & 100,00 & 100,00 \\
\hline Item & \multicolumn{4}{|c|}{ Composição química das rações completas } \\
\hline Matéria seca $(\% \mathrm{MN})$ & 91,58 & 90,39 & 90,43 & 90,47 \\
\hline Matéria orgânica (\%MS) & 94,85 & 93,46 & 93,44 & 93,42 \\
\hline Matéria mineral (\%MS) & 5,15 & 6,54 & 6,56 & 6,58 \\
\hline Proteína bruta (\%MS) & 9,63 & 9,63 & 9,77 & 9,91 \\
\hline Extrato etéreo $(\% \mathrm{MS})$ & 4,39 & 4,35 & 4,38 & 4,40 \\
\hline Fibra em detergente neutro (\%MS) & 46,77 & 46,47 & 46,50 & 46,52 \\
\hline Fibra em detergente ácido (\%MS) & 21,96 & 21,91 & 21,97 & 22,03 \\
\hline $\mathrm{FDN}_{\mathrm{CP}}(\% \mathrm{MS})^{3}$ & 45,74 & 45,45 & 45,47 & 45,49 \\
\hline PIDN $(\% \mathrm{MS})^{4}$ & 0,0010 & 0,0010 & 0,0010 & 0,0010 \\
\hline PIDA $(\% \mathrm{MS})^{5}$ & 0,0022 & 0,0022 & 0,0022 & 0,0022 \\
\hline LDA $(\% \mathrm{MS})^{6}$ & 2,60 & 2,57 & 2,56 & 2,54 \\
\hline Carboidratos totais $(\% \mathrm{MS})$ & 80,83 & 79,48 & 79,30 & 79,11 \\
\hline Carboidratos não fibrosos (\%MS) & 35,09 & 34,03 & 33,83 & 33,63 \\
\hline Nutriente digestível total (\%MS) & 69,97 & 68,86 & 68,83 & 68,80 \\
\hline
\end{tabular}

${ }^{\mathrm{I}} \mathrm{TG}=$ torta de girassol, teores de substituição da proteína da torta de girassol pela proteína do farelo de algodão, em 0 ; 24; 48 e $72 \%$. ${ }^{2}$ As rações completas foram calculadas de acordo com a relação volumoso:concentrado de 65:35\%; ${ }^{3} \mathrm{FDN}_{\mathrm{CP}}(\% \mathrm{MS})=$ porcentagem de fibra em detergente neutro corrigido para cinzas e proteínas na matéria seca; ${ }^{4} \mathrm{PIDN}(\% \mathrm{MS})=$ porcentagem de proteína indigestível em nitrogênio neutro na matéria seca; ${ }^{5} \mathrm{PIDA}(\% \mathrm{MS})=$ porcentagem de proteína indigestível em detergente ácido na matéria seca; ${ }^{6} \mathrm{LDA}(\% \mathrm{MS})=$ porcentagem de lignina em solução de ácido sulfúrico $72 \%$ na matéria seca.

Fonte: Elaboração dos autores.

A fração $\mathrm{A}$, ou compostos nitrogenados não proteicos (NNP), foi obtida após o tratamento de $0,5 \mathrm{~g}$ de amostra com $50 \mathrm{~mL}$ de água por 30 minutos e, depois, adição de $10 \mathrm{~mL}$ da solução de ácido tricloroacético (TCA) a 10\%, deixando-se em repouso por mais 30 minutos. Em seguida, foi filtrada em papel de filtro de filtragem rápida, lavando-se o resíduo com $50 \mathrm{~mL}$ de solução de TCA diluído a $1 \%$. Logo após determinou-se o teor de nitrogênio do resíduo mais o papel. A fração A ou NNP (\%PB) foi calculada pela diferença entre o teor de N-total e o de Ninsolúvel no TCA (Sniffen et al., 1992).

A fração B1+B2 foi calculada pela fórmula $\mathrm{B} 1+\mathrm{B} 2(\% \mathrm{~PB})=\% \mathrm{TCA}-\% \mathrm{PIDN}$ descrita por Sniffen et al. (1992). A fração B3 (\%PB) foi calculada pela diferença entre a proteína insolúvel em detergente neutro (PIDN) e a proteína insolúvel em detergente ácido (PIDA); a fração $\mathrm{C}$ foi considerada como a proteína insolúvel em detergente ácido (PIDA), ambas descritas por Sniffen et al. (1992).

Os parâmetros de cinética de degradação ruminal in vitro das rações foram estimados por meio do método semiautomático de produção cumulativa de gases descrito por Pell e Schofield (1993). O inóculo ruminal foi obtido de quatro bovinos machos $1 / 2$ Gir x $1 / 2$ Holandês, castrados, pesando em média $554 \mathrm{~kg}$ e canulados no rúmen, mantidos em pastagem, suplementados com $1 \mathrm{~kg}$ dia $^{1}$ de ração concentrada contendo milho, farelo de soja, ureia, sal mineral, provida de bebedouros coletivos.

A solução tampão, descrita por Mcdougall (1948), foi preparada e aquecida a $39^{\circ} \mathrm{C}$, sob gaseificação contínua com $\mathrm{CO}_{2}$. Em cada frasco de incubação, foram colocados $0,3 \mathrm{~g}$ de amostra, $28,125 \mathrm{~mL}$ de meio de cultura e $3,125 \mathrm{~mL}$ de inóculo ruminal. Para os ajustes de variação, 
foram incubados frascos considerados branco, contendo as soluções de incubação sem substrato. Os frascos foram hermeticamente fechados utilizando-se rolhas de borracha. A pressão dos gases produzidos pela fermentação do substrato e acumulada nos frascos foi mensurada por meio de um manômetro (após despressurização inicial), nos tempos uma, duas, três, quatro, cinco, seis, nove, 12, 18, 24, 30, 36, $48,60,72,84$ e 144 horas, realizando-se despressurização após cada leitura.

O modelo matemático de Gompertz foi utilizado para a avaliação da cinética de fermentação, yij = $\mu+\tau i+\beta j+i j$, em que: $\mu$ é a média geral (ou uma constante); yij é o valor observado na parcela que recebeu o i-ésimo tratamento no $\mathrm{j}$ ésimo bloco; $\tau$ i é um parâmetro que representa o i-ésimo efeito de tratamento; $\beta \mathrm{j}$ é um parâmetro que representa o j-ésimo efeito de bloco; ij é um componente do erro aleatório, associado ao $\mathrm{j}$ ésimo bloco e i-ésimo tratamento, tal que ij NID $(0, \sigma 2)$. O procedimento não linear do $R(R$ Development Core Team, 2011) foi utilizado para ajustar os dados ao modelo.

Os fracionamentos dos carboidratos totais e da proteína bruta foram conduzidos em delineamento em blocos ao acaso. Os dados foram submetidos à análise de variância e à análise de regressão a $5 \%$ de significância, utilizando-se o pacote estatístico PROC GLM e PROC REG do Statistical... (2001).
As análises estatísticas da cinética de degradação ruminal in vitro foram realizadas com o uso do programa estatístico R (R Development, 2011), sendo utilizado o delineamento em blocos ao acaso (contendo quatro tratamentos, quatro períodos e cinco repetições por amostra). Os dados foram submetidos à análise de normalidade, aditividade e homocedasticidade (pacote ExpDes), e as médias comparadas pelo teste de Tukey a 5\% de probabilidade.

\section{RESULTADOS E DISCUSSÃO}

Entre as rações avaliadas, o teor de carboidratos totais decresceu linearmente $(\mathrm{R} 2=0,93)$ conforme o aumento de torta de girassol (Tab. 3). As rações com 48 e $72 \%$ de torta de girassol apresentaram os menores valores de carboidratos totais em razão do maior teor de proteína bruta e de extrato etéreo presentes na torta de girassol. Os valores encontrados neste trabalho para carboidratos totais da torta de girassol $(48,10 \% \mathrm{MS})$ corroboram os valores relatados por Mizubuti et al. (2011) (47,45\%MS). Considerando-se que os carboidratos representam a principal fonte de energia para a fermentação microbiana, transformando-se em ácidos graxos voláteis $(\mathrm{AGV})$, as rações contendo 0 e $24 \%$ foram superiores às rações contendo 48 e $72 \%$ de torta de girassol.

Tabela 3. Fracionamento de carboidratos totais de rações suplementares contendo torta de girassol

\begin{tabular}{|c|c|c|c|c|c|c|c|}
\hline \multirow{2}{*}{ Item } & \multicolumn{4}{|c|}{ Teores de inclusão de TG, $(\%)$} & \multirow{2}{*}{$\mathrm{CV}(\%)$} & \multirow{2}{*}{ ER } & \multirow{2}{*}{$\mathrm{R}^{2}$} \\
\hline & 0 & 24 & 48 & 72 & & & \\
\hline $\mathrm{CHO}$ & 73,74 & 68,34 & 62,06 & 58,67 & 2,25 & $\hat{Y}=73,428-0,215 x$ & 0,93 \\
\hline $\mathrm{A}+\mathrm{B} 1$ & 57,50 & 44,03 & 33,97 & 27,93 & 12,08 & $\hat{Y}=55,673-0,412 x$ & 0,83 \\
\hline B2 & 16,14 & 24,18 & 27,93 & 30,58 & 20,92 & $\hat{Y}=17,65-0,196 x$ & 0,53 \\
\hline $\mathrm{C}$ & 0,10 & 0,12 & 0,16 & 0,16 & 20,74 & $\hat{Y}=0,104-0,00085 x$ & 0,43 \\
\hline
\end{tabular}

$\mathrm{CHO}=$ carboidratos totais $(\% \mathrm{MS}) ; \mathrm{A}+\mathrm{B} 1=$ carboidratos não fibrosos $(\% \mathrm{CHO}) ; \mathrm{B} 2=$ componentes disponíveis correspondentes à fração potencialmente degradável $(\% \mathrm{CHO}) ; \mathrm{C}=$ fração indigestível da parede celular $(\% \mathrm{CHO})$; $\mathrm{ER}=$ equação de regressão; $\mathrm{R}^{2}=$ coeficiente de determinação; $\mathrm{TG}=$ torta de girassol.

Fonte: Elaboração dos autores.

Os carboidratos não fibrosos (CNF) correspondem aos carboidratos solúveis em detergente neutro, ou seja, fazem parte do núcleo celular, composto de açúcares (glicose, frutose), ácidos orgânicos e outros carboidratos de reserva de plantas, tais como amido, sacarose e frutosanas (Sniffen et al., 1992). Nesse sentido, os $\mathrm{CNF}$ representam a frações $\mathrm{A}+\mathrm{B} 1$, e os carboidratos fibrosos (CF) compõem as frações B2 e C. A fração A é composta por açúcares e a fração B1 é composta por amido e glucana (Sniffen et al., 1992).

A fração $\mathrm{A}+\mathrm{B} 1$, que representa a porção de rápida degradação ruminal, fonte de energia para os microrganismos ruminais (suporte inicial), 
apresentou efeito linear negativo $(\mathrm{R} 2=0,83)$, variando de 57,50 a 27,93\%, respectivamente, para 0 e $72 \%$ TG em relação aos carboidratos totais. Esse fato pode ser justificado pelo elevado teor de FDNCP $(39,36 \% \mathrm{MS})$ presente na torta de girassol, quando comparada ao farelo de soja $(19,14 \% \mathrm{MS})$ e o milho grão $(22,84 \% \mathrm{MS})$ (Tab.1). Assim, essa diferença estrutural nos ingredientes, possivelmente, proporcionou valores menores de degradação ruminal para a fração $\mathrm{A}+\mathrm{B} 1$ das rações com maiores teores de inclusão de torta de girassol.

A fração B2 é composta pelos carboidratos fibrosos da parede celular, que são de disponibilidade ruminal lenta, e, consequentemente, susceptíveis aos efeitos da taxa de passagem (Sniffen et al., 1992). Dessa forma, influenciam no fornecimento de energia no rúmen, que pode afetar a síntese microbiana $\mathrm{e}$ o desempenho animal (Ribeiro et al., 2001). O teor crescente de FDNCP $(16,25 ; 24,30 ; 28,09$; 30,74 , respectivamente para as rações contendo 0; 24; 48 e $72 \%$ TG, Tab. 2) contribui para o aumento dos carboidratos fibrosos na ração. Esse fato pode parcialmente explicar os resultados da fração B2 (dos carboidratos) que apresentaram efeito linear crescente $(\mathrm{R} 2=0,53)$. Neste estudo, o teor de 39,36\% FDNCP na MS presente na torta de girassol influenciou a composição da fração B2 das rações suplementares.
A fração C representa a parede celular indisponível, acarretando a indigestibilidade dos carboidratos estruturais dessas rações; assim, rações contendo altos teores dessa fração induzem a menores ingestões voluntárias (Van Soest, 1994). Observou-se efeito linear crescente na fração $C$ dos carboidratos $(\mathrm{R} 2=0,43)$, com as rações 48 e $72 \%$ de TG apresentando os maiores valores $(0,16)$ dessa fração. A torta de girassol apresentou maior teor de lignina $(4,59 \%)$ dentre os alimentos que compuseram as rações estudadas (Tab. 1), assim esperava-se que as rações contendo os maiores teores de torta de girassol apresentassem maiores quantidades dessa fração.

Em relação aos compostos nitrogenados, a fração A (nitrogênio não proteico, NNP) das rações estudadas apresentou efeito linear crescente $(\mathrm{R} 2=$ 0,47) (Tab. 4). As rações contendo 48 e $72 \%$ de TG, respectivamente, apresentaram valores de 26,72 e $24,86 \%$ de fração A, o que implicaria fontes nitrogenadas disponíveis para bactérias fermentadoras de carboidratos fibrosos, as quais utilizam amônia para atendimento de suas exigências proteicas. Nocek e Russell (1988) afirmaram que, quando a disponibilidade de proteínas rapidamente degradáveis é elevada, é necessário concomitantemente o adequado suprimento de carboidratos com rápida degradação para o perfeito sincronismo de fermentação de carboidratos e proteínas.

Tabela 4. Fracionamento de proteínas, expressas em proteína bruta total $(\% \mathrm{~PB})$ de rações suplementares contendo torta de girassol

\begin{tabular}{|c|c|c|c|c|c|c|c|}
\hline \multirow{2}{*}{ Item } & \multicolumn{4}{|c|}{ Teores de inclusão de TG, $(\%)$} & \multirow[t]{2}{*}{$\mathrm{CV}(\%$} & \multirow[t]{2}{*}{ ER } & \multirow[t]{2}{*}{$\mathrm{R}^{2}$} \\
\hline & 0 & 24 & 48 & 72 & & & \\
\hline $\mathrm{A}$ & 12,40 & 15,53 & 26,72 & 24,86 & 32,61 & $\hat{\mathrm{Y}}=12,589+0,202 \mathrm{x}$ & 0,47 \\
\hline $\mathrm{B} 1+\mathrm{B} 2$ & 87,55 & 84,43 & 73,25 & 75,11 & 8,09 & $\hat{Y}=87,359-0,202 x$ & 0,47 \\
\hline B3 & 0,035 & 0,032 & 0,026 & 0,019 & 40,32 & $\hat{\mathrm{Y}}=0,03$ & \\
\hline $\mathrm{C}$ & 0,017 & 0,009 & 0,007 & 0,006 & 45,30 & $\hat{\mathrm{Y}}=0,0145-0,0001376 \mathrm{x}$ & $\overline{0,44}$ \\
\hline
\end{tabular}

$\mathrm{A}=$ nitrogênio não proteico; $\mathrm{B} 1+\mathrm{B} 2=$ proteína degradável; $\mathrm{B} 3=$ proteína lentamente degradável; $\mathrm{C}=$ proteína indisponível; $\mathrm{ER}=$ equação de regressão; $\mathrm{R}^{2}=$ coeficiente de determinação; $\mathrm{TG}=$ torta de girassol.

Fonte: Elaboração dos autores.

A fração $\mathrm{B} 1+\mathrm{B} 2$, composta por proteína solúvel não ligada ao FDN (B1) e a resultante da subtração da proteína insolúvel em tampão menos a proteína bruta total menos o FDN (B2), depende diretamente da degradação da parede celular do alimento, que, por sua vez, depende da taxa de passagem dele (Sniffen et al., 1992). Nesse contexto, a inclusão da torta de girassol pode ter influenciado $(\mathrm{R} 2=0,47)$ o efeito linear decrescente observado para essa fração, uma vez que esse ingrediente promove o aumento nos teores de FDNCP presentes nas rações estudadas (Tab. 2), suscitando a passagem da proteína de forma intacta pelo rúmen, a qual poderá ser absorvida posteriormente no intestino do animal.

A fração B3 da proteína propicia maior fluxo de aminoácidos para o intestino, pois essa fração é degradada lentamente no rúmen (Carvalho et al., 
2008), possuindo taxa de degradação ruminal de 0,02 a $1,0 \% \mathrm{~h}^{-1}$ (Sniffen et al., 1992), e, portanto, apresenta elevado "escape", sendo potencial fonte de aminoácidos no intestino. Essa fração é representada pelas extensinas, prolaminas e pelas proteínas de ligação de parede celular que apresentam lenta taxa de degradação, sendo assim, digeridas principalmente nos intestinos. Não foi observada diferença significativa para os valores da fração B3 neste estudo.

A fração $\mathrm{C}$ corresponde à proteína associada à lignina, complexo tanino proteína e produtos oriundos da reação de Maillard, altamente resistentes às enzimas microbianas e indigestíveis ao longo do trato gastrointestinal (Sniffen et al., 1992; Licitra et al., 1996). Neste ensaio, houve efeito linear negativo para a fração $\mathrm{C}(\mathrm{R} 2=0,47)$. Esse fato pode ser devido ao menor teor de PIDA na torta de girassol $(0,0016 \% \mathrm{MS})$ (Tab. 1$)$ e ao maior teor de PIDA presente no milho $(0,0042 \% \mathrm{MS})$. Tais características demonstram que há viabilidade na inclusão da torta de girassol em rações suplementares para bovinos.

A avaliação de fontes de proteína degradáveis no rúmen advinda de rações compostas por coprodutos torna-se importante para sua utilização na formulação de rações completas destinadas à alimentação de animais ruminantes, uma vez que se deve analisar a fração nitrogenada disponível para os microrganismos e a fração não degradada no rúmen, que fica disponível para a digestão enzimática no intestino do animal.

Segundo Pell e Schofield (1993), a técnica in vitro de produção de gases considera a conversão de todas as principais fontes de carboidratos, como monossacarídeos, polissacarídeos, amido, pectina, celulose e hemicelulose, em gás carbônico $\left(\mathrm{CO}_{2}\right)$ e gás metano $\left(\mathrm{CH}_{4}\right)$ e, também, a reação dos ácidos graxos voláteis com $\mathrm{O}$ tampão bicarbonato. O volume acumulado de produção de gases ( $\mathrm{mL} \mathrm{g}^{-1} \mathrm{MS}$ ) é apresentado na Fig. 1. A partir de duas horas pós-incubação, o volume de gases produzido em cada tempo começou a diferenciar-se; porém, o pico de produção de gases para cada ração foi diferente. O pico de produção de gases para ração com $0 \%$ de TG foi de $49,06 \mathrm{~mL} \mathrm{~g}^{-1} \mathrm{MS}, 18 \mathrm{~h}$ após incubação; $24 \%$ TG foi de $37,00 \mathrm{~mL}$ g $_{-1} \mathrm{MS}, 18 \mathrm{~h}$ após incubação; $48 \%$ TG foi de $31,18 \mathrm{~mL} \mathrm{~g}^{-1} \mathrm{MS}$, nove horas após incubação, e a ração com $72 \%$ de TG apresentou pico de 25,42 $\mathrm{mL} \mathrm{g}^{-1} \mathrm{MS}, 18 \mathrm{~h}$ após incubação.

Maurício et al. (2003) afirmaram que a produção cumulativa de gases assume que a produção de massa celular microbiana e de gás é proporcional à quantidade de substrato digerido; em outras palavras, o volume de gases corresponde à completa digestão do substrato ( $\mathrm{mL} \mathrm{g} \mathrm{g}^{-1} \mathrm{MS}$ ) (parâmetro "a"). Pode-se observar, na Tab. 5, que o maior volume de gases correspondente à completa digestão do substrato ( $\mathrm{mL} \mathrm{g}^{-1} \mathrm{MS}$ ) ocorreu na ração suplementar contendo $0 \%$ TG $(\mathrm{R} 2=0,98)$.

A ração suplementar contendo $0 \%$ de TG continha a maior quantidade de milho dentre as rações estudadas e, nesse sentido, observa-se que a fermentação dos carboidratos não fibrosos, em sua maior parte, foi proveniente do milho (Tab. 1), gerando maior produção de gás, $311,05 \mathrm{~mL} \mathrm{~g}^{-1}$ MS, seguido de $250,37 \mathrm{~mL} \mathrm{~g}^{-1}$ MS provenientes da ração com $24 \%$ de TG. Os menores valores foram de 201,60 e $169,99 \mathrm{~mL} \mathrm{~g}^{-1} \mathrm{MS}$, respectivamente para $48 \%$ e $72 \%$ TG (Tab. 5), que podem ter sido ocasionados por fatores tais como: maior quantidade de FDNCP e fração B2 dos carboidratos, pela fermentação da proteína solúvel que gera amônia como principal metabólito; falta de sincronismo entre carboidratos e proteínas ou teor de extrato etéreo da ração suplementar.

Para o parâmetro "b", que corresponde à taxa específica semelhante à taxa de degradação (R2= 0,98), Tab. 5, indica-se que a máxima taxa específica semelhante à taxa de degradação seria obtida com $61,84 \%$ TG. A degradabilidade da proteína é um importante fator a se considerar, a fim de se avaliar o aproveitamento dela pelo animal, pois indica o potencial do alimento a ser utilizado. Fortaleza et al. (2013), ao estudarem a substituição parcial do farelo de soja pela torta de nabo forrageiro nos teores de $0 ; 25 ; 50$ e $75 \%$, não verificaram diferença entre os tratamentos para esse parâmetro. Goes et al. (2010), ao estudarem a degradabilidade efetiva de grãos de oleaginosas e suas tortas, relataram que a torta de soja, de girassol e de crambre apresentaram, respectivamente, as degradabilidades de 75,60; 84,$52 ; 60,43$ a $5 \% \mathrm{~h}^{-1}$, enquanto Beran et al. (2005), ao avaliarem torta de girassol com uma e duas prensagens, relataram valores de degradabilidade efetiva de 58,38 e 67,27, respectivamente, a $5 \% \mathrm{~h}^{-1}$. 


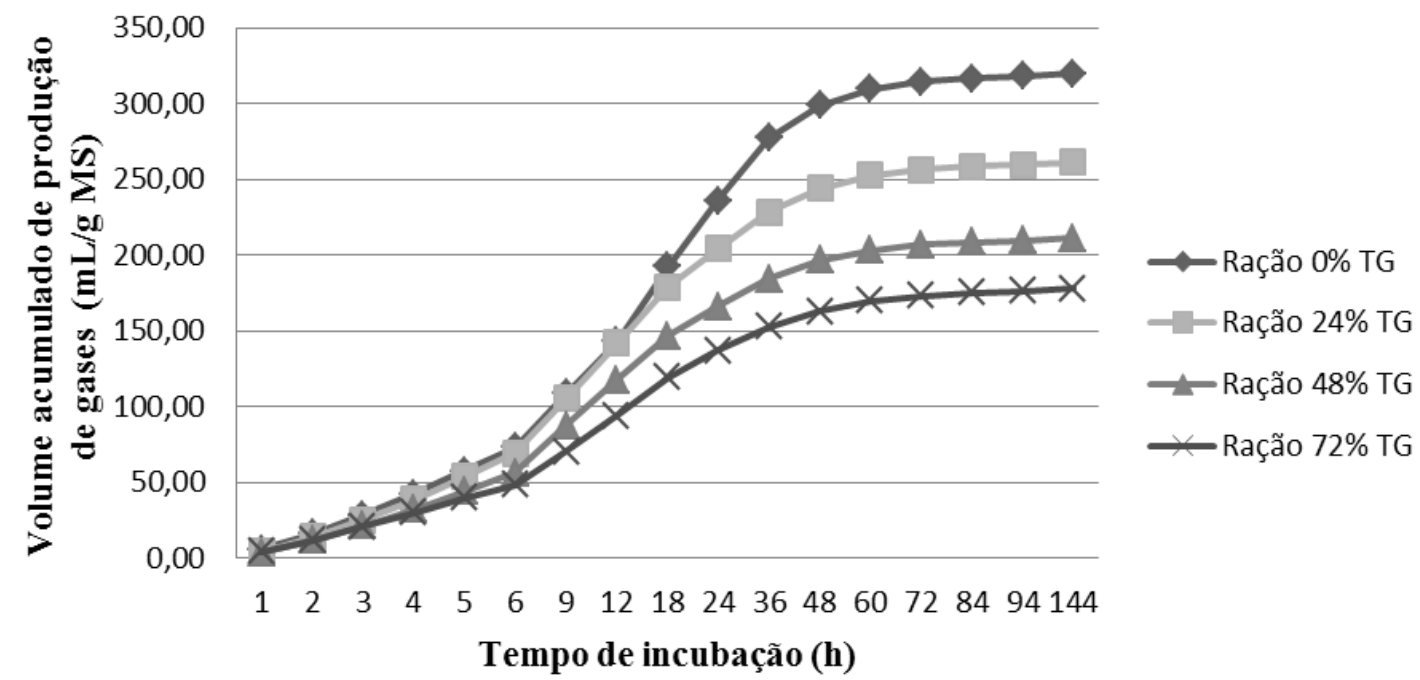

Figura 1. Volume acumulado de produção de gases (mL/g MS) em função do tempo de incubação (horas) de rações suplementares contendo torta de girassol.

Fonte: Elaboração dos autores.

Tabela 5. Parâmetros de degradação ruminal de rações suplementares contendo torta de girassol

\begin{tabular}{lccccccc}
\hline \multirow{2}{*}{ Parâmetro } & \multicolumn{4}{c}{ Teores de inclusão de TG, $(\%)$} & \multirow{2}{*}{ CV $(\%)$} & ER & $\mathrm{R}^{2}$ \\
\cline { 2 - 5 } & 0 & 24 & 48 & 72 & & & \\
\hline $\mathrm{a}(\mathrm{mL} / \mathrm{g}$ MS $)$ & 311,05 & 250,37 & 201,60 & 169,99 & 7,99 & 1 & 0,98 \\
$\mathrm{~b}\left(\% \mathrm{~h} \mathrm{~h}^{-1}\right)$ & 2,79 & 2,91 & 2,91 & 2,66 & 5,59 & 2 & 0,98 \\
$\mathrm{c}(\mathrm{mL} / \mathrm{h})$ & 0,095 & 0,123 & 0,126 & 0,114 & 12,4 & 3 & 0,98 \\
\hline
\end{tabular}

$\mathrm{ER}=$ equação de regressão; $\mathrm{R}^{2}=$ coeficiente de determinação; $\mathrm{TG}=$ torta de girassol; $\mathrm{a}=$ volume de gases correspondente à completa digestão do substrato (assíntota); $b=$ taxa específica semelhante à taxa de degradação; $c=$ fator constante de eficiência microbiana que descreve o ponto de inflexão da curva a uma determinada velocidade de produção de gases. ${ }^{1} \hat{\mathrm{Y}}=304,040851-1,966422 \mathrm{x} ;{ }^{2} \hat{\mathrm{Y}}=2,78433517+0,00986174 \mathrm{x}-0,00015946 \mathrm{x}^{2} ;{ }^{3} \hat{\mathrm{Y}}=0,09577298$ $+0,00114773 \mathrm{x}-0,00001719 \mathrm{x}^{2}$.

Fonte: Elaboração dos autores.

Para o fator constante de eficiência microbiana que descreve o ponto de inflexão da curva a uma determinada velocidade de produção de gases (parâmetro "c"), pode-se estimar que o máximo parâmetro "c" seria obtido com $66,77 \%$ de torta de girassol $(\mathrm{R} 2=0,98) \quad(\mathrm{Tab} .5)$. Esse dado permite inferir que, até à inclusão de $66,77 \%$ de torta de girassol, a eficiência microbiana não seria afetada; a partir desse teor, a torta de girassol tende a interferir na eficiência microbiana. Possivelmente, este fato seja decorrente da composição bromatológica do girassol, uma vez que esse alimento possui alto teor de extrato etéreo, $13,33 \%$.

\section{CONCLUSÃO}

A inclusão da torta de girassol nas rações suplementares, nos teores estudados, influenciou nas frações dos carboidratos, das proteínas e nos parâmetros de degradação ruminal. Caso haja a disponibilidade desse ingrediente, ele pode ser adicionado à ração suplementar de bovinos sem prejuízo nos parâmetros nutricionais e metabólicos.

\section{REFERÊNCIAS}

BERAN, F.H.B.; SILVA, L.D.F.; RIBEIRO, E.L.A. et al. Degradabilidade ruminal "in situ" da matéria seca, matéria orgânica e proteína bruta de alguns suplementos concentrados usados na alimentação de bovinos. Semin. Cienc. Agrar., v.26, p.405-418, 2005.

CARVALHO, G.G.P.D.; GARCIA, R.; PIRES, A.J.V. et al. Fracionamento de proteínas de silagem de capim-elefante emurchecido ou com farelo de cacau. Cienc. Anim. Bras., v.9, p.648-656, 2008.

CHANDLER, P. Energy prediction of feeds by forage testing explorer. Feedstuffs, v.62, p.12, 1990. 
FORTALEZA, A.; SILVA, L.; BARBERO, R. et al. Efeito da torta de nabo forrageiro sobre a cinética de fermentação e degradação ruminal in vitro. Arch. Zootec., v.62, p.131-142, 2013.

GOES, R.H.T.B.; SOUZA, K.A.; PATUSSI, R.A. et al. Degradabilidade in situ dos grãos de crambe, girassol e soja, e de seus coprodutos em ovinos. Acta Sci. Anim. Sci., v.32, p.271-277, 2010.

LICITRA, G.; HERNANDEZ, T.M.; VAN SOEST, P.J. Standardization of procedures for nitrogen fractionation of ruminant feeds. Anim. Feed Sci. Technol., v.57, p.347-358, 1996.

MAURÍCIO, R.M.; PEREIRA, L.G.R.; GONCCALVES, L.C. et al. Potencial da técnica in vitro semi-automática de produção de gases para avaliação de silagens de sorgo (Sorghum bicolor (L.) Moench). Rev. Bras. Zootec., v.32, p.1013-1020, 2003.

MCDOUGALL, E.I. Studies on ruminant saliva. 1. The composition and output of sheep's saliva. Biochem. J., v.43, p.99-109, 1948.

MELLO, R.; NÖRNBERG, J.L.; QUEIROZ, A.C.D. et al. Composição química, digestibilidade e cinética de degradação ruminal das silagens de híbridos de girassol em diferentes épocas de semeadura. Rev. Bras. Zootec., v.35, p.1523-1534, 2006.

MESACASA, A.C.; ZERVOUDAKIS, J.T.; ZERVOUDAKIS, L.K.H. et al. Torta de girassol em suplementos múltiplos para bovinos em pastejo no período seco do ano: desempenho produtivo e viabilidade econômica. Rev. Bras. Saude Prod. Anim., v.13, p.1116-1179, 2012.

MIZUBUTI, I.Y.; RIBEIRO, E.L.A.; PEREIRA, E.S. et al. Cinética de fermentação ruminal in vitro de alguns co-produtos gerados na cadeia produtiva do biodiesel pela técnica de produção de gás. Semin. Cienc. Agrar., v.32, Sup1., p.2021-2028, 2011.

NOCEK, J.E.; RUSSELL, J.B. Protein and energy as an integrated system. relationship of ruminal protein and carbohydrate availability to microbial synthesis and milk production. J. Dairy Sci., v.71, p.2070-2107, 1988.

OLIVEIRA, A.A. Parâmetros comportamentais e fisiológicos de vacas em lactação suplementadas com torta de girassol. 2010. 60f. Dissertação (Mestrado em Ciência Animal) - Programa de Pós Graduação em Ciência Animal, Universidade Estadual de Londrina, Londrina, PR.
PELL, A.N.; SCHOFIELD, P. Computerized monitoring of gas production to measure forage digestion in vitro. J. Dairy Sci., v.76, p.1063-1073, 1993.

PEREIRA, E.S.; MIZUBUTI, I.Y.; AZAMBUJA, R.E.L. et al. Estimative of the nutritional value of agroindustrial byproducts by using in vitro gas production technique. Semin. Cienc. Agrar., v.34, p.391-398, 2013.

$\mathrm{R}$ DEVELOPMENT core team: a languge and environment for statistical computing. Version 3.3.1 Vienna: R Fondation for Statistical Computing, 2011.

RIBEIRO, K.G.; PEREIRA, O.G.; VALADARES FILHO, S.D.C. et al. Caracterização das frações que constituem as proteínas e os carboidratos, e respectivas taxas de digestão, do feno de capim-tifton 85 de diferentes idades de rebrota. Rev. Bras. Zootec., v.30, p.589-595, 2001.

SANTOS, A.X.; SILVA, L.D.F.; LANÇANOVA, J.A.C. et al. Efeitos da suplementação de torta de girassol para vacas lactantes: desempenho produtivo e análise econômica. Semin. Cienc. Agrar., v.33, Supl.2, p.3401-3410, 2012.

STATISTICAL analysis system. Version 8.2.Cary: SAS Institute, 2001.

SILVA, M.D.L.O.E.; FARIA, M.A.D.; MORAIS, A.R.D. et al. Crescimento e produtividade do girassol cultivado na entressafra com diferentes lâminas de água. Rev. Bras. Eng. Agric. Ambien., v.11, p.482-488, 2007.

SILVA, D.J.; QUEIROZ, A.C. Análise de alimentos: métodos químicos e biológicos. 3.ed. Viçosa: Universidade Federal de Viçosa, 2002. 235p.

SNIFFEN, C.J.; O'CONNOR, J.D.; VAN SOEST, P.J. et al. A net carbohydrate and protein system for evaluating cattle diets: II. carbohydrate and protein availability. J. Anim. Sci., v.70, p.3562-3577, 1992.

VAN SOEST, P.J. Nutritional ecology of the ruminant. 2.ed. New York: Cornell University Press, 1994. 476p. 